\title{
Numerical analysis of the in-plane behaviour of TRM-strengthened masonry walls
}

\author{
X. Wang \\ SAHC Masters Course, University of Minho, Guimarães, Portugal \\ B. Ghiassi \& D.V. Oliveira \\ ISISE, University of Minho, Guimarães, Portugal
}

\begin{abstract}
Application of Fibre Reinforced Polymers (FRPs) for Externally Bonded Reinforcement (EBR) of masonry structures has received extensive attention during the past decade. FRPs are found to be hardly compatible with historical masonry. As an alternative, the use of innovative composite materials based on continuous fibres embedded in inorganic matrices (also referred as TRM) has found recent attention. However, only few information is available in the literature regarding the mechanical properties and effectiveness of TRMs for strengthening of masonry structures. This paper presents the numerical simulation of the nonlinear behaviour of TRM-strengthened masonry panels under in-plane actions. The modelling strategy is initially validated by simulating tensile response of TRMs and validation with available experimental results. The effect of different tension softening models on the tensile response of TRMs is also investigated. The adopted modelling strategy is then used to predict the in-plane response of masonry panels strengthened with TRM composites under compressive and monotonic lateral-loading. The FE model predicts the key parameters in the behaviour of strengthened masonry, including the load-displacement response, crack development, failure mode and reinforcement contribution to the global performance. The results, presented and critically discussed, indicate that strengthening based on TRM significantly improves the performance of masonry walls under shear loading.
\end{abstract}

\section{INTRODUCTION}

Externally Bonded Reinforcement (EBR) of existing unreinforced masonry (URM) structures with FRP composites has received extensive attention as an alternative to conventional strengthening methods. The main advantages of using FRPs come from the material's high strength/stiffness to weight ratio and ease of application. However, FRPs have several drawbacks for application to historical structures, such as hygrothermal incompatibility, poor performance at high temperatures, relatively high cost of epoxy resins, and no reversibility of installation [D'Ambrisi et al. 2013, Ombres 2011, Triantafillou 2011]. Those drawbacks limit the use of FRPs for strengthening of masonry and especially for historical structures. As an alternative, the use of innovative composite materials based on fabrics or grids embedded in inorganic matrices has been recently promoted and received extensive attention [D'Ambrisi et al. 2013, De Caso et al. 2012]. This new generation of composite systems is referred with several terms such as Textile Reinforced Concrete (TRC), Textile Reinforced Mor$\operatorname{tar}$ (TRM) or Fabric Reinforced Cementitious Matrix (FRCM). TRM is developed as an evolution of ferrocement, where the mortar matrix is reinforced with open meshes (grids) of continuous dry fibres [Nanni
2012]. TRMs are expected to fulfil moisture compatibility and reversibility requirements for strengthening of masonry and historical structures [Carozzi \& Poggi 2015, De Felice et al. 2014]. Although, these composites have been previously used for strengthening of reinforced concrete elements, their application to masonry is rather recent and their effectiveness in performance improvement is not clear yet.

Two key components of TRMs are the matrix and the fibre mesh or grid. The matrix is generally a lime-based or a cement-based mortar. Cement-based mortars are more suitable for structural strengthening of existing reinforced concrete and possibly existing masonry buildings. On the other hand, lime-based mortars are generally proposed for historical and old masonry due to their relatively low mechanical properties. A wide range of fibres are produced and used for reinforcement in TRM systems including steel, glass, $\mathrm{PBO}$, carbon, aramid, etc. The fibres can be either short dispersed or continuous in the form of a mesh or fabric also referred as textile. The continuous fibre reinforcement which has numerous possible configurations is often referred as fibre architecture [D'Ambrisi et al. 2015, Hartig et al. 1998].

Besides the recent attention on the use of TRM composites, various aspects including numerical modelling techniques and suitable constitutive models still 
need to be studied [Bertolesi et al. 2014]. The mechanical performance of TRM-strengthened masonry is mainly dependent on [Hartig et al. 1998] (i) the bond behaviour at the fibre/mortar interface; (ii) the bond behaviour at mortar/substrate interface; and (iii) the tensile response of TRM. This paper presents a numerical investigation on the tensile behaviour of TRM composites and shear performance of masonry panels after strengthening with TRMs. The effect of different modelling techniques and constitutive models on the tensile response of TRMs are deeply investigated. The most appropriate technique, after validation with experimental results, is selected for simulating the nonlinear response of TRM-strengthened panels under in-plane loads. The effect of strengthening on the nonlinear load-displacement response and failure mode of the panels are presented and discussed.

\section{TENSILE BEHAVIOUR OF TRMS}

The tensile behaviour of TRMs can be presented by a tri-linear stress-strain curve [Bertolesi et al. 2014]. In the first phase, the load is carried primarily by the mortar and increases linearly according to the Young's modulus of the mortar until mortar cracks. In the second phase, the mortar undergoes a multi-cracking process resulting in transfer of stresses from the reinforcing fabric to the mortar, with some debonding at the fabric-mortar interface. In the third phase, mortar is fully cracked and the composite system behaves almost linearly until failure occurs due to the progressive rupture of the roving fibre filaments and debonding of the fabric from the matrix. In this phase, the load is carried almost exclusively by the fabric. This section is aimed at deeply investigation of these mechanisms following a numerical approach.

\subsection{Finite element modelling strategy}

The finite elements analysis (FEA) is a powerful tool for material modelling and analysis of structural response. With the aim of having an insight into the observed experimental variability, a comprehensive FE numerical analysis was utilized for real tests to study the tensile behaviour of TRM composites. Different variables in numerical model that can affect the mechanical behaviour in tension were examined leading to a deep understanding of the test results.

The analysis was performed using the commercial software package DIANA 9 [2014]. A series of models following a macro-modelling approach were used to interpret the experimental results from Carozzi \& Poggi [2015]. The TRM composites were modelled using quadrilateral 8-noded curved shell elements (denoted as CQ40S in DIANA) for mortar and embedded grid reinforcement (assuming perfect bond) for the grids (Figure 1).

\subsection{Reference experimental results}

Carozzi \& Poggi [2015] performed several tensile tests on TRM composites made of cementitious mortar

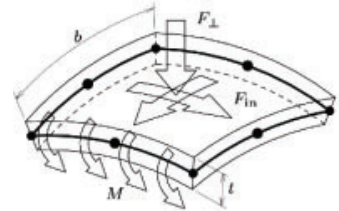

(a)

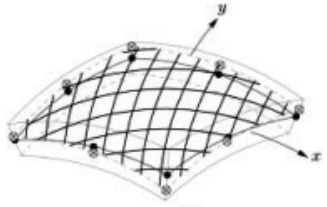

(b)
Figure 1. (a) Quadrilateral 8 noded curved shell elements in DIANA (b) grid reinforcement in curved shell elements

Table 1. Materials mechanical properties [Carozzi \& Poggi 2015].

\begin{tabular}{llll}
\hline & Test specimen & $\begin{array}{l}\text { Failure stress } \\
(\mathrm{MPa})\end{array}$ & $\begin{array}{l}\mathrm{E} \\
(\mathrm{GPa})\end{array}$ \\
\hline PBO & Grid strip* & 3397 & - \\
Mortar & Tensile test & 4.75 & 6 \\
& Compressive test & 15 & - \\
\hline
\end{tabular}

$* 4 \mathrm{~cm}$ width with 4 rovings, roving in the warp direction.

and PBO (polyparaphenylene benzobisoxazole) fibre grids. The PBO fibres were organized in an unbalanced net made with $10 \mathrm{~mm}$ and $20 \mathrm{~mm}$ spaced rovings. The materials mechanical properties were obtained by performing tensile tests on fibre strips (made of 4 rovings) and indirect tensile (Brazilian test) and compressive tests on mortar specimens (Table 1).

The tensile coupons had nominal size of $400 \times 40 \times 10 \mathrm{~mm}$ with a PBO mesh in the middle layer (Figure 2a). In the experiment, a significant variability in the transversal section (both width and thickness) was observed which led to a quite wide experimental scatter in the load-displacement curves (Figure $2 \mathrm{~b}$ ). However, the typical tri-linear tensile behaviour associated to TRM composites was observed in all the specimens.

\subsection{Material properties, boundary condition and analysis procedure}

The total strain rotating crack model (based on smeared crack modelling) was used for modelling the nonlinear response of mortar. As no specific constitutáve law is available for tension softening behaviour of mortars in TRM composites, an exponential softening (Figure 3a) and a nonlinear softening with plateau according to Japan Society of Civil Engineers (JSCE 2010) (Figure 3b), were used and the results were compared. A parabolic model was used (Figure 3c) for the compressive behaviour. The main mechanical properties were derived from the experimental tests (Table 1). For the tensile strength of mortar a factor of $75 \%$ was applied to the Brazilian test results as the results obtained from these tests are generally higher than the direct tensile strength. A linear elastic behaviour until failure was assumed for the grid fibre reinforcements.

The adopted boundary conditions and loading scheme were set up according to the tests as shown 

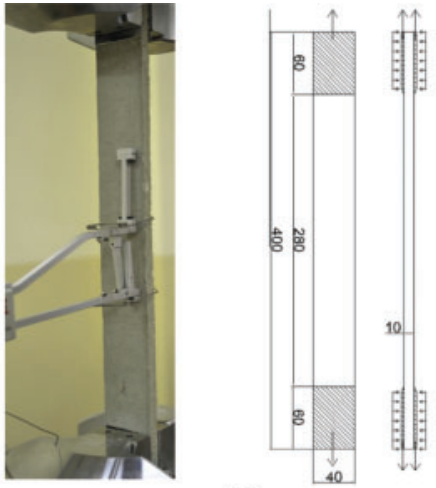

(a)

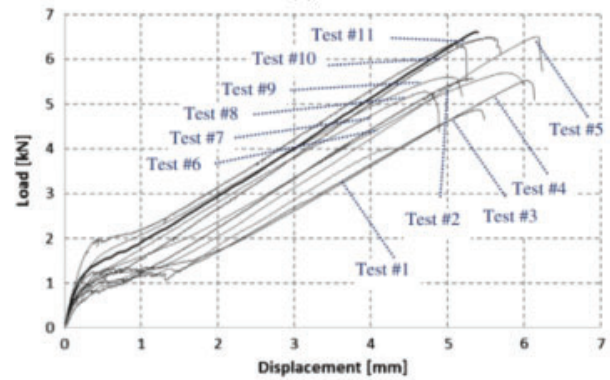

(b)

Figure 2. (a) Tensile test set-up (in mm); (b) Experimental load-displacement curves [Bertolesi et al. 2014, Carozzi \& Poggi 2015].

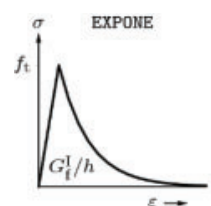

(a)

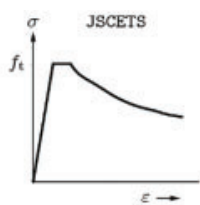

(b)

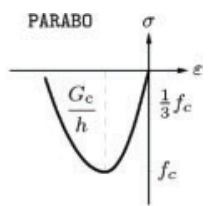

(c)
Figure 3. Implemented material models for total strain crack model: (a) exponential tensile softening (b) JSCE tensile softening with plateau (c) parabolic compression.

in Figure 2a. The nodes at bottom end of the model are fixed in vertical direction and then an incremental vertical displacement is monotonically applied on top of the model by performing a static nonlinear analysis. The specimen self-weight was not included in the model because the extra load due to self-weight was considered insignificant when compared to the applied load. Vertical displacement was incrementally applied (displacement control) on the top of the specimen to simulate the tensile response.

\subsection{Results and discussion}

\subsubsection{Exponential softening model}

The exponential softening is one of the most common constitutive laws used for representing the softening behaviour of concrete as shown by Hordijk [1991] (Figure 3a). Two different post-cracking conditions,

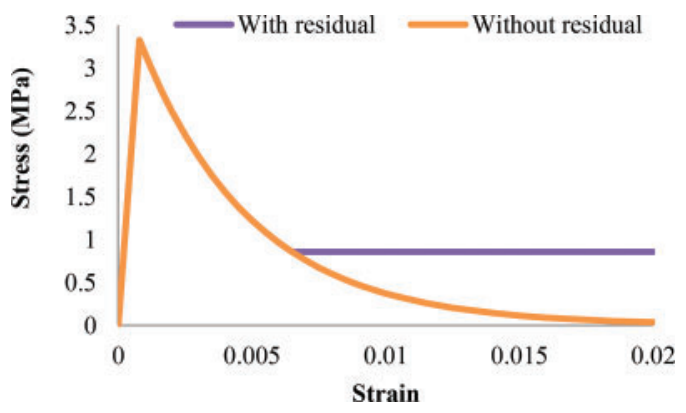

Figure 4. Exponential models with and without residual.

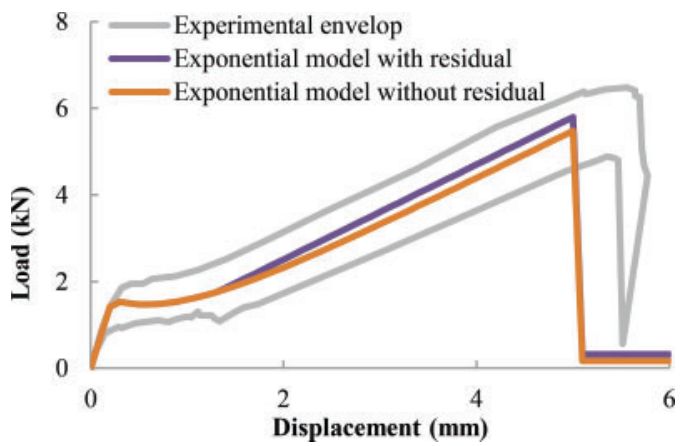

Figure 5. Influence of exponential model in simulating the tensile behaviour of TRM composites.

with and without residual tensile strength, were adopted for the mortar in this study (Figure 4). The numerical load-displacement curves are compared with the envelope of the experimental results in Figure 5 . The results have a good agreement with experimental data, not only in the stiffness and post-cracking behaviour but also at the peak load and ultimate displacement. The numerical curves generally fall within the experimental envelope and show the typical three stages identified by different stiffness values. As expected, the load-displacement curves for the two models are the same in the first and second phase, but a small difference is observed in third phase and the peak load. This difference is due to the different residual stress in post-cracking conditions. Although both models seem to produce acceptable results, the exponential model without residual is used hereafter for numerical simulations as is more common in numerical simulations.

\subsubsection{JSCE softening model}

In previous numerical studies, e.g [Bertolesi et al. 2014], the numerical results for the second phase of tensile response has received more attention. From the experimental point of view, the cracks in the mortar start to grow and propagate in this phase, and stiffness increases smoothly in some cases by the contribution of grid (in some other cases, stiffness is constant with small fluctuations and have been accurately reproduced by exponential model). From the theoretical 
point of view, tensile stresses in reinforced mortar might not suddenly drop as in exponential softening models. The stress-strain curve might enter a plateau area to present the development of the first crack to small multiple cracks in the mortar. Thereafter, the tensile stresses decrease slowly with crack opening. The tension softening model proposed by JSCE considers this mechanism, see Figure 6, and is thus used in this section. The softening curve after the plateau is presented as follows in this model (JSCE 2010):

$\sigma=f t\left(\varepsilon_{t u} / \varepsilon\right)^{c}$

where: $\sigma=$ total stress; $\varepsilon=$ total strain $f_{t}=$ tensile strength, $\varepsilon_{t u}=$ end of plateau strain, $c=$ the power parameter (default value $=0.4$ for reinforced concrete).

A comparison is made here between the results obtained by using exponential model and JSCE model, see Figure 7. The numerical load-displacement curves present a similar tri-linear behaviour as test results in both exponential and JSCE model. According to the previous discussion, as expected, JSCE model presents a smooth increase of stiffness in early second phase and higher tensile stresses until failure. The effect of parameter $\mathrm{c}$ on the tensile response is also investigated and presented next.

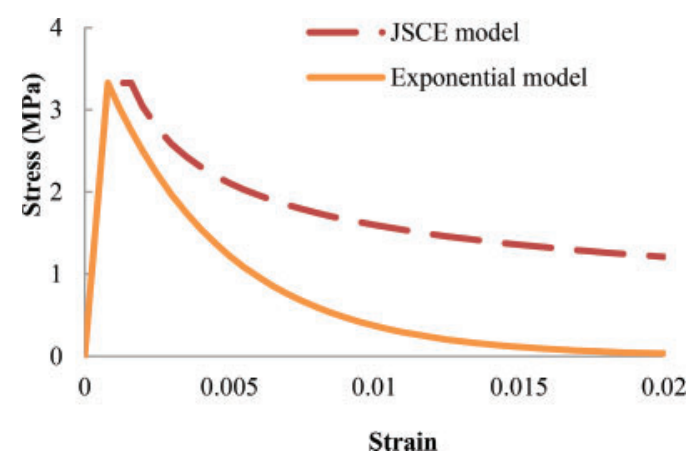

Figure 6. Exponential and JSCE models.

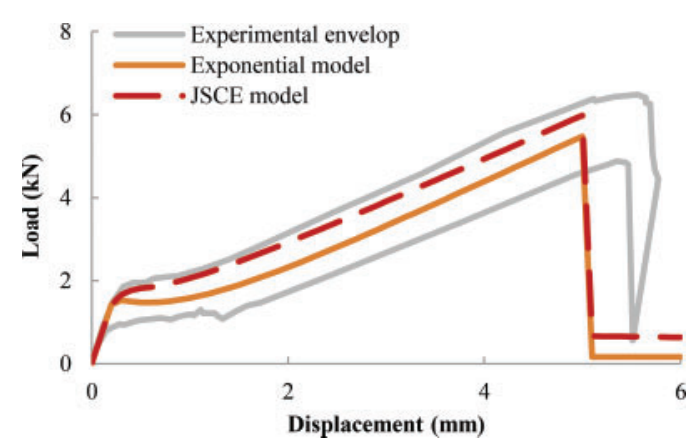

Figure 7. Comparison of exponential and JSCE models in simulating the tensile behaviour of TRM composites.
Four different values are used for the parameter c in Eq. 1 (Figure 8) and its effect on the numerical response is presented in Figure 9. The loaddisplacement curves show that numerical result is closest to the average test results when $\mathrm{c}=0.6$. For model with $\mathrm{c}=0.2$ and $\mathrm{c}=0.4$, the stress-strain curve shows softening with large residual stress and much higher fracture energy. For model with $c=0.8$, the stress-strain curve shows softening with small residual stress and lower fracture energy.

\section{IN-PLANE BEHAVIOUR OF TRM-STRENGTHENED MASONRY WALLS}

This section is devoted to numerical analysis of inplane behaviour of masonry panels strengthened with TRM composites. A hypothetical URM panel was assumed in this section with $100 \mathrm{~mm}$ thickness and dimensions of $1000 \times 1000 \mathrm{~mm}^{2}$, see Figure 10 . The URM panel was strengthened at both sides with $5 \mathrm{~mm}$ TRM layers with $50 \mathrm{~mm}$ spaced PBO grids. The behaviour of the URM and TRM-strengthened panel under in-plane actions and pre-compression was compared and discussed. Both masonry and TRM layers were modelled by CQ40S elements. A perfect bond was assumed between the masonry and TRM layers.

A macro-modelling approach was used for simulating the behaviour of masonry in this study.

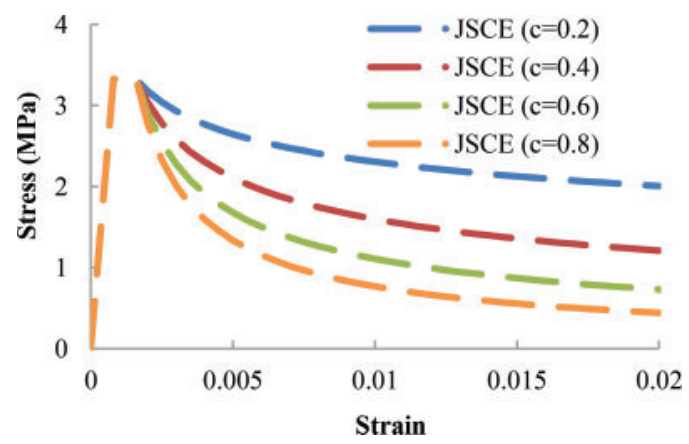

Figure 8. JSCE model with different parameter.

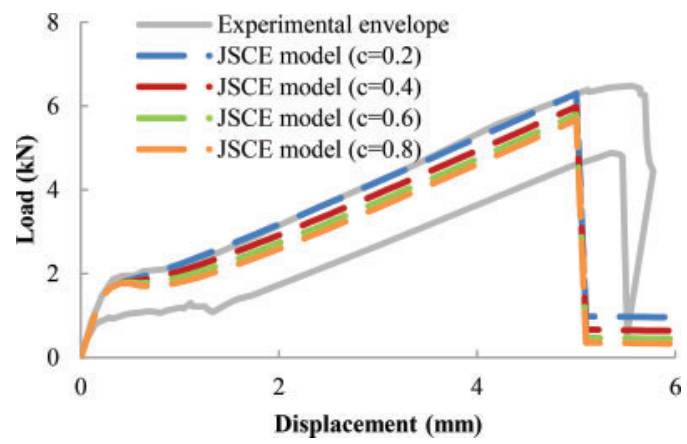

Figure 9. Influence of JSCE softening model in tensile response of TRM composites. 
The softening anisotropic elasto-plastic continuum model proposed by Lourenço \& Rots [Lourenço 2000, Lourenço \& Rots 1998] was used for modelling the masonry. A Hill-type yield criterion and a Rankinetype yield criterion were used in compression and in tension, respectively. The mechanical parameters (Table 2) of masonry are based on experimental data from material characterization tests performed at University of Macau [Fat 2012] on common clay bricks and mortars used in Macau and numerical data from Milani et al. [Milani et al. 2006]. Note that $\mathrm{x}$ is the head joint direction and $\mathrm{y}$ is the bed joint direction in this Table.

TRM layers were modelled using the same strategy presented in last section. Fibre grids were modelled as embedded in cementitous mortar assuming a perfect bond between fibres and mortar. The material data of TRM and PBO grids are the same as presented in Table 1.

The hypothetical panel is assumed fixed at the bottom and clamped at top with a stiff steel beam without allowing rotation (Figure 10), shear and 0.3 $\mathrm{MPa}$ pre-compression loading are initially applied, then an incremental horizontal displacement is monotonically applied on top of the wall by performing a static nonlinear analysis.

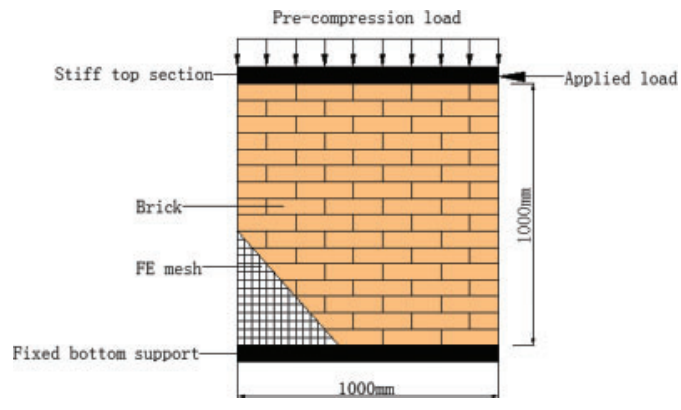

Figure 10. Geometry and loading condition of the hypothetical wall.
Comparison of numerical load-displacement curves for URM and TRM-strengthened panels are shown in Figure 11. The peak load of the strengthened panel is $68.9 \mathrm{kN}$ showing $117.5 \%$ increment in comparison to the URM panel (with the peak load of $31.67 \mathrm{kN}$ ). Three critical points can be distinguished in the loaddisplacement curve of the strengthened panel, see Figure 11: masonry cracking, mortar cracking and PBO grids tensile rupture. In the first phase, the load is nearly elastic until masonry reaches the tensile strength and cracking occurs in the masonry. Then, the load is carried primarily by the mortar until reaching ultimate tensile strength and occurrence of cracking. At the third phase, the cracks are distributed along the mortar surface and the PBO fibres reach the ultimate tensile strength in some regions. This is followed by progressive rupture of the fibres until ultimate displacement. The corresponding stress level in different material at each critical point is shown in Figures 12-14.

The principal tensile strain of URM wall at the peak load is shown in Figure 14a. As expected in this low

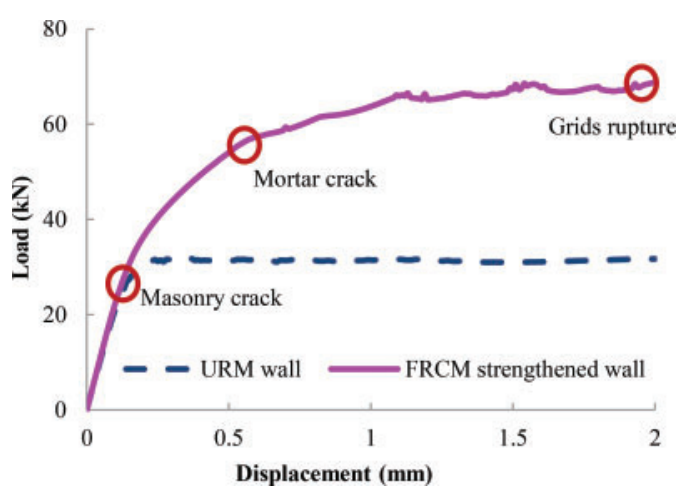

Figure 11. Numerical load-displacement curves for URM and TRM strengthened panels under $0.30 \mathrm{MPa}$ pre-compression.

Table 2. Mechanical parameters of masonry (brick with mortar connection).

Masonry mechanical parameters

Young's Modulus

Poisson's ratio

Tensile strength along $x$-direction

Tensile strength along $y$-direction

Compressive strength along $x$-direction

Compressive strength along $y$-direction

Fracture energy in tension along $x$-direction

Fracture energy in tension along $y$-direction

Fracture energy in compression along $x$-direction

Fracture energy in compression along $y$-direction

Factor that determines the shear stress contribution to the tensile failure

Factor which couples the normal compressive stresses

Factor which controls shear stress contribution to compressive failure

Factor that specifies the equivalent plastic strain corresponding to the peak compressive stress

$\begin{array}{ll}(E) & 8000 \mathrm{MPa} \\ (v) & 0.15 \\ (\sigma t x) & 0.25 \mathrm{MPa} \\ (\sigma t y) & 0.35 \mathrm{MPa} \\ (\sigma c x) & 7.80 \mathrm{MPa} \\ (\sigma c y) & 8.50 \mathrm{MPa} \\ \left(G_{f x}\right) & 0.018 \mathrm{~N} \mathrm{~mm} / \mathrm{mm}^{2} \\ \left(G_{f y}\right) & 0.054 \mathrm{Nmm} / \mathrm{mm}^{2} \\ \left(G_{f c x}\right) & 15.00 \mathrm{Nmm} / \mathrm{mm}^{2} \\ \left(G_{f c y}\right) & 20.00 \mathrm{Nmm} / \mathrm{mm}^{2} \\ (\alpha) & 1.0 \\ (\beta) & -1.0 \\ (\gamma) & 3.0 \\ (k p) & 0.0012\end{array}$




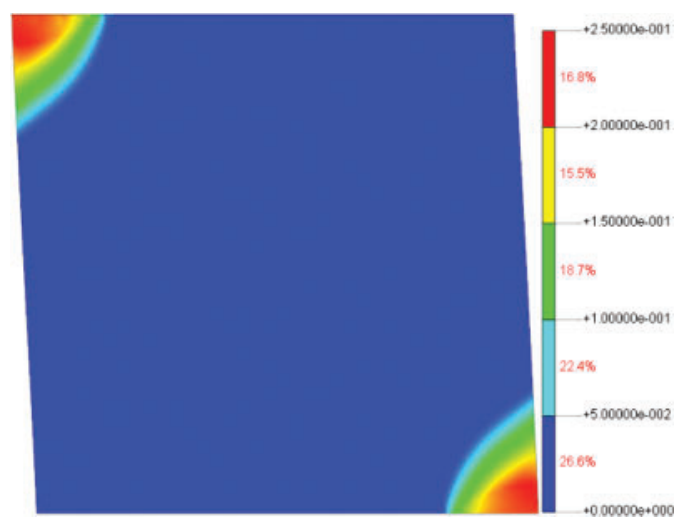

Figure 12. Tensile stress in masonry in vertical direction: masonry crack at displacement $=0.1 \mathrm{~mm}$.

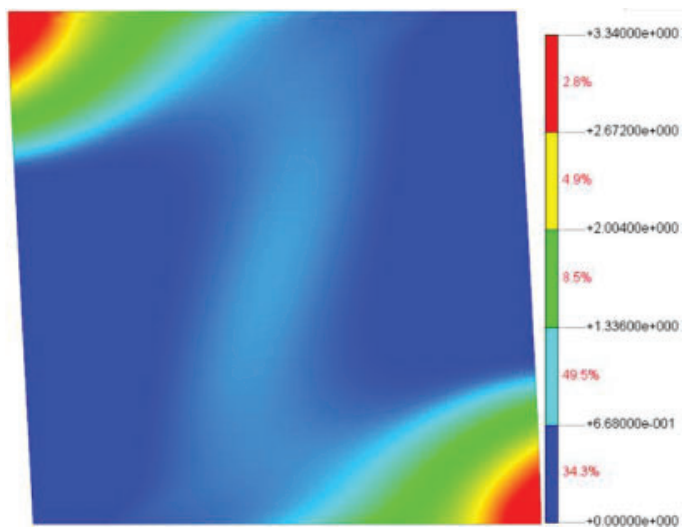

Figure 13. Principal tensile stress in mortar: mortar crack at displacement $=0.5 \mathrm{~mm}$.

compression level, the failure mode of URM panel is rocking at the base. Figure 14b shows principal tensile strain of masonry in the strengthened panel at the peak load. The failure mode of TRM-strengthened wall mainly is rocking failure without local failure. It should be note that TRM strengthening avoid the local failure in masonry but failure mode is not changed in this case. However, change of failure mode in masonry wall with strengthening has been observed in many cases [Hamid 2005, Marcari et al. 2007] and needs to be better investigated in case of TRM-strengthened masonry.

\section{CONCLUSIONS AND RECOMMENDATIONS}

\subsection{Conclusions}

An extensive numerical investigation was conducted in this study to investigate the tensile and bond behaviour of fabric reinforced cementitious matrix (TRM) composites and application in strengthening for the masonry structures. The work involved: (1) application and proposal of a rational FE model for

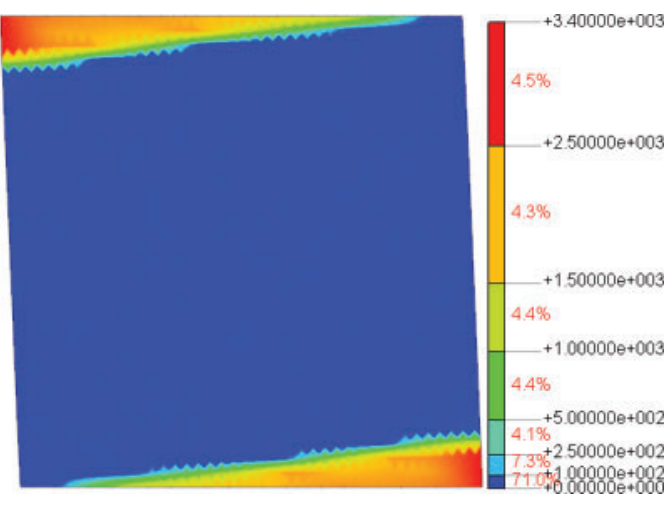

Figure 14. Grids stress in vertical direction: grids rupture at displacement $=2 \mathrm{~mm}$.

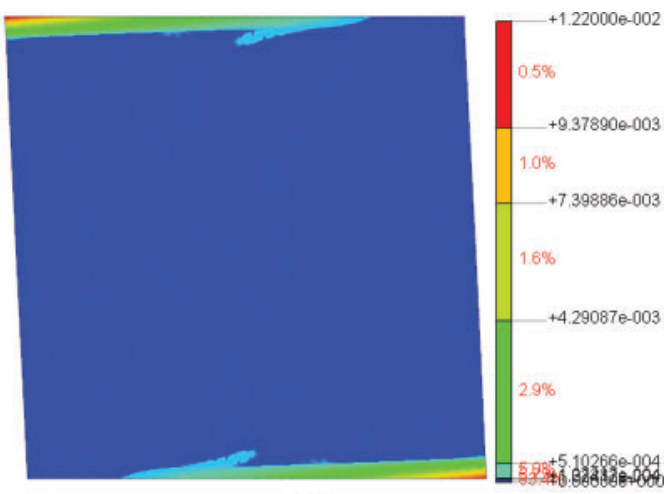

(a)

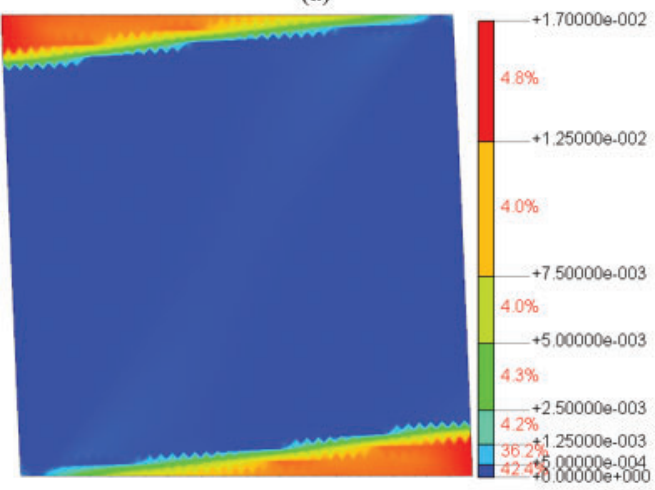

(b)

Figure 15. Principal tensile strain in masonry at peak load: (a) URM panel at displacement $=0.3 \mathrm{~mm}$; (b) TRM-strengthened masonry panel at displacement $=2 \mathrm{~mm}$.

simulating the strengthened masonry structures by verifying the FE results with experimental results taken from literature; (2) calibration of the model and deep understanding of the test results by studying different variables in numerical model (3) prediction of nonlinear response of TRM-strengthened 
masonry panels under compressive and shear loading.

The work carried out in this research contributes to the discussion on using FE models to investigate TRM technique for strengthening masonry. In summary, the main findings are:

1. The modelling strategy adopted to model the tensile behaviour of TRM composites presented accurate predictions in the full non-linear response with regard to the reference experimental tests. Although all the adopted exponential models produced suitable results, development of a suitable tension softening model or modification of the exiting one for TRM composites seems to be needed.

2. The FE results show that TRM is effective in increasing the load capacity of shear panels. With TRM strengthening, the failure mode of wall may also change which should be considered at the design stage.

\subsection{Limitations and recommendations}

Although curved shell elements were used in the FE model, the studies were only on the in-plane responses of the strengthened panels. Out of plane loading or non-symmetric models can be the subject of future studies using the same modelling strategy.

The performance of strengthened masonry walls was investigated by performing static nonlinear (pushover) analysis. As the seismic behaviour of the strengthened structures is of great concern, future research can to be extended to include cyclic loading and nonlinear dynamic analysis. Several studies can be thus performed including the effect of cyclic loading on the bond behaviour between TRM and masonry; testing strengthened walls under cyclic loading; and making further improvements to the FE model to include load reversals.

Analytical models for TRM-strengthened shear walls do not exist yet. Few available analytical models are for certain failure modes (such as diagonal tension cracking) and have been verified with only a limited number of experimental results. A precise analytical model considering all possible failure modes in TRM-strengthened masonry walls can be of great interest.

\section{REFERENCES}

Bertolesi E, Carozzi FG, Milani G, Poggi G. 2014. Numerical modelling of Fabric Reinforce Cementitious Matrix composites (FRCM) in tension. Construction and Building Materials 70, 531-548.
Carozzi, F.G. \& Poggi, C. 2015. Mechanical properties and debonding strength of Fabric Reinforced Cementitious Matrix (FRCM) systems for masonry strengthening. Composites: Part B 70, 215-230.

D’Ambrisi A, Feo L, Focacci F. 2012. Experimental analysis on bond between PBO-FRCM strengthening materials and concrete. Compos B Eng,; 44(1):524-32.

D'Ambrisi A, Focacci F, Caporale A. 2013. Strengthening of masonry-unreinforced concrete railway bridges with PBP-FRCM materials. Compos Struct;107:193-204.

De Caso Y, Basalo FJ, Matta F, Nanni A. 2012. Fibre reinforced cement-based composite system for concrete confinement. Construction and Building Materials,; 32:5565.

De Felice G, De Santis S, Garmendia L, Ghiassi B, Larrinaga P, Lourenço PB, Oliveira DV, Papanicolaou, CG. 2014. Mortar-based systems for externally bonded strengthening of masonry, Materials and Structures, 47(12), pp. 2021-2037.

DIANA. 2014. Displacement analysis finite element software. V. 9.6, TNO Building Division, Delft, The Netherlands.

Fat, KK, 2012.A study of masonry structure of Macau, Final Year Project Report in University of Macau.

Hamid AA, El-Dakhakhni WW, Hakam ZHR, Elgaaly M. 2005. Behaviour of composite unreinforced masonryfibre-reinforced polymer wall assemblages under In-Plane Loading. J. Compos. Constr, 9(1): 73-83.

Hartig J, Haußler-Combe U, Schicktanz K. 2008. Influence of bond properties on the tensile behaviour of textile reinforced concrete. Cement Concr Compos; 30(10):898-906.

Hordijk DA. 1991. Local Approach to Fatigue of Concrete. $\mathrm{PhD}$ thesis, Delft University of Technology.

Lourenço PB, 2000. Anisotropic Softening Model for Masonry Plates and Shells. Journal of Structural Engineering, Vol. 126, No. 9, September, pp. 1008-1016.

Lourenço PB \& Rots G, Blaauwendraad J. 1998. Continuum model for masonry: parameter estimation and validation. Journal of Structural Engineering (ASCE); 124:642-52.

Marcari G, Manfredi G, Prota A, Pecce 2007. M. In-plane shear performance of masonry panels strengthened with FRP. Composites: Part B 38 887-901.

Milani G, Rotunno T, Sacco E, Tralli A. 2006. Failure load of FRP strengthened masonry walls: Experimental results and numerical models. SDHM.; 2:29-50.

Nanni A. 2012. FRCM strengthening - a new tool in the concrete and masonry repair toolbox. Concr Int Des Constr; 34(4):43-9.

Ombres L. 2011. Flexural analysis of reinforced concrete beams strengthened with a cement based high strength composite material. Compos Struct; 94(1):143-55.

Triantafillou TC. 2011. A new generation of composite materials as alternative to fibre reinforced polymers for strengthening and seismic retrofitting of structures. Proc: composite materials. A vision for the future. SpringerVerlag London Limited. 